\title{
ERROR ANALYSIS IN THE NUMERICAL SOLUTION OF 3D CONVECTION-DIFFUSION EQUATION BY FINITE DIFFERENCE METHODS
}

\author{
E. C. Romão ${ }^{a}$, \\ J. B. Campos-Silva ${ }^{b}$, \\ and L. F. M. de Moura ${ }^{a}$ \\ ${ }^{a}$ Universidade Estadual de Campinas \\ Faculdade de Engenharia Mecânica \\ Departamento de Engenharia Térmica e \\ Fluidos \\ Rua Mendeleyev, 200 \\ Cidade Universitária "Zeferino Vaz" \\ Distrito de Barão Geraldo \\ CEP:13083-860 Campinas SP Brasil \\ estaner23@yahoo.com.br

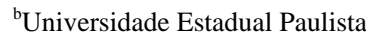 \\ Departamento de Engenharia Mecânica \\ Av. Brasil Centro, 56 \\ CEP - 15385-000 - Ilha Solteira SP Brasil
}

\section{ABSTRACT}

In this work an error analysis for numerical solution of 3D convectiondiffusion equation by finite difference methods has been done. The backward, the forward and the central difference schemes are applied for three applications: a case with diffusion dominant corresponding to high diffusion coefficients and two cases with convection dominant or with low diffusion coefficients. In the second application the convective coefficients are function only of the diffusion coefficient that in dimensionless form is named Reynolds numbers. In the third application the convective coefficients are function of both the Reynolds number and of the space. The three applications have analytical solutions to facilitate numerical comparisons of the solutions.

Keywords: Finite Difference Method, Error Analysis, Reynolds Numbers, Convection-Diffusion.

\section{NOMENCLATURE \\ $x, y, z \quad$ space coordinates \\ $f$ source \\ $u$ temperature \\ $L_{2} \quad$ Global norm \\ $L_{\infty} \quad$ Maximum error \\ $\mathfrak{R}$ real numbers \\ Re Reynolds number}

\section{Greek symbols}

$\Omega \quad$ three-dimensional domain

\section{Subscripts}

$\mathrm{i}, \mathrm{i}+1$ position of node in discretization

\section{INTRODUCTION}

The Finite Difference Method (FDM) is a powerful tool to solve fluid mechanics and heat transfer problems. Several authors already presented excellent results from the application of FDM in 1D, 2D and 3D problems of Fluid mechanics and Heat Transfer.

In Hsu (2006) the 3D inverse non-Fourier heat conduction problem are solved by Finite Difference Method and showing excellent results because it is purely diffusive problems. Excellent results are also presented in Yang et all (2002), were one particular integral formulations are presented for $2 \mathrm{D}$ and $3 \mathrm{D}$ transient potential flow (heat conduction) analysis. The results of the analysis are compared with an alternative formulation developed using the volume integral conversion approach, obtained excellent results.

Among them Gupta and Zhang (2000) utilized an explicit fourth order finite difference scheme for the solution of 3D convection-diffusion equation. In Romão et all (2008) a FDM was applied to numerical solution of 1D transient diffusion equation obtaining good results. In Chung (2002) several problems of Fluid Mechanics were solved by the application of FDM, including solution of the Laplace and the Burgers equations. In Hon and Chen (2003) a numerical solution of a convection-diffusion equation by the Boundary Knot Method is compared with its analytical solution.

In this work, three variants of the Finite Difference Method (FDM) are applied to an error analysis in the solution of the convection-diffusion equation. They are the backward, the forward and central difference schemes. Three applications are considered: one with diffusion predominant and the other two with convection predominant, a case with convective coefficients function only of the Reynolds number and another with convective coefficients depending on the Reynolds number and the position. 
The performance of each scheme is analyzed and discussed.

In this work we consider the solution of a 3D convection-diffusion problem modeled by the general equation:

$$
\begin{gathered}
a \frac{\partial^{2} u}{\partial x^{2}}+b \frac{\partial^{2} u}{\partial y^{2}}+c \frac{\partial^{2} u}{\partial z^{2}}+d \frac{\partial u}{\partial x}+e \frac{\partial u}{\partial y}+g \frac{\partial u}{\partial z}+ \\
+h u=f(x, y, z)
\end{gathered}
$$

with $a=a(x, y, z), \quad b=b(x, y, z), \quad c=c(x, y, z)$, $d=d(x, y, z), e=e(x, y, z), g=g(x, y, z), h=h(x, y, z)$ and $u=u(x, y, z)$.

\section{FINITE DIFFERENCE METHOD}

The basic idea of finite difference methods is simple: derivatives in differential equations are written in terms of discrete quantities of dependent and independent variables, resulting in simultaneous algebraic equations with all unknowns prescribed at discrete mesh points for the entire domain.

In this item, we present three variants of the finite difference method (Chung (2002), Smith (1971) and Fortuna (2000)) for deriving equations.

\subsection{Taylor Series - Finite Difference Methods}

Consider a function $u(x)$ and its derivative at point $x$,

$$
\frac{\partial u(x)}{\partial x}=\lim _{\Delta x \rightarrow 0} \frac{u(x+\Delta x)-u(x)}{\Delta x}
$$

If $u(x+\Delta x)$ is expanded in Taylor Series around $u(x)$, we obtain

$$
u(x+\Delta x)=u(x)+\Delta x \frac{\partial u(x)}{\partial x}+\frac{(\Delta x)^{2}}{2} \frac{\partial^{2} u(x)}{\partial x^{2}}+\ldots
$$

Substituting (3) into (2) yields

$$
\frac{\partial u(x)}{\partial x}=\lim _{\Delta x \rightarrow 0}\left(\frac{\partial u(x)}{\partial x}+\frac{\Delta x}{2} \frac{\partial^{2} u(x)}{\partial x^{2}}+\ldots\right)
$$

Or it is seen from (3) that

$$
\begin{aligned}
& \frac{u(x+\Delta x)-u(x)}{\Delta x}=\frac{\partial u(x)}{\partial x}+\frac{\Delta x}{2} \frac{\partial^{2} u(x)}{\partial x^{2}}+\ldots \Rightarrow \\
& \frac{u(x+\Delta x)-u(x)}{\Delta x}=\frac{\partial u(x)}{\partial x}+O(\Delta x)
\end{aligned}
$$

The derivative $\partial u(x) / \partial x$ in (5) is of first order in $\Delta x$, indicating that the truncation error $O(\Delta x)$ goes to zero like the first power in $\Delta x$. The finite difference form given by (2), (4) and (5) is said to be of the first order accuracy.

We may write $u$ in Taylor series at $i+1$ and $i-1$,

$$
u_{i+1}=u_{i}+\Delta x\left(\frac{\partial u}{\partial x}\right)_{i}+\frac{\Delta x^{2}}{2}\left(\frac{\partial^{2} u}{\partial x^{2}}\right)_{i}+\frac{\Delta x^{3}}{3 !}\left(\frac{\partial^{3} u}{\partial x^{3}}\right)_{i}+\ldots
$$

$$
u_{i-1}=u_{i}-\Delta x\left(\frac{\partial u}{\partial x}\right)_{i}+\frac{\Delta x^{2}}{2}\left(\frac{\partial^{2} u}{\partial x^{2}}\right)_{i}-\frac{\Delta x^{3}}{3 !}\left(\frac{\partial^{3} u}{\partial x^{3}}\right)_{i}+\ldots
$$

Rearranging Eq. (6) and after neglecting terms of order greater than 2, we arrive at the forward difference:

$$
\left(\frac{\partial u}{\partial x}\right)_{i}=\frac{u_{i+1}-u_{i}}{\Delta x}+O(\Delta x)
$$

Likewise, from (7), we have the backward difference:

$$
\left(\frac{\partial u}{\partial x}\right)_{i}=\frac{u_{i}-u_{i-1}}{\Delta x}+O(\Delta x)
$$

A central difference is obtained by subtracting (7) from (6):

$$
\left(\frac{\partial u}{\partial x}\right)_{i}=\frac{u_{i+1}-u_{i-1}}{2 \Delta x}+O\left(\Delta x^{2}\right)
$$

It is seen that the truncation errors for the forward and backward differences are first order, whereas the central difference yields a second order truncation error (Chung, 2000).

Finally, by adding (6) and (7), we have

$$
\frac{u_{i+1}-2 u_{i}+u_{i-1}}{\Delta x^{2}}=\left(\frac{\partial^{2} u}{\partial x^{2}}\right)_{i}+\frac{(\Delta x)^{2}}{12}\left(\frac{\partial^{4} u}{\partial x^{4}}\right)_{i}+\ldots
$$

This leads to the finite difference formula for the second derivative with second order accuracy,

$$
\left(\frac{\partial^{2} u}{\partial x^{2}}\right)_{i}=\frac{u_{i+1}-2 u_{i}+u_{i-1}}{\Delta x^{2}}+O\left(\Delta x^{2}\right)
$$

\section{DERIVATION OF FINITE DIFFERENCE SCHEME EQUATIONS}

In that follows, the mathematical formulation by FDM in three considered variants is presented for the convection-diffusion Equation (1). 


\subsection{Forward Difference Scheme - FDS}

By substitution of Eqs. (8) and (12) in Eq. (1), we obtain the forward difference scheme as

$$
\begin{aligned}
& \left(\frac{a}{\Delta x^{2}}+\frac{d}{\Delta x}\right) u_{i+1, j, k}+\left(\frac{b}{\Delta y^{2}}+\frac{e}{\Delta y}\right) u_{i, j+1, k}+ \\
& \frac{b}{\Delta y^{2}} u_{i, j-1, k}+\left(\frac{c}{\Delta z^{2}}+\frac{g}{\Delta z}\right) u_{i, j, k+1}+\frac{a}{\Delta x^{2}} u_{i-1, j, k}+ \\
& \frac{b}{\Delta y^{2}} u_{i, j-1, k}+\left(\frac{c}{\Delta z^{2}}+\frac{g}{\Delta z}\right) u_{i, j, k+1}+\frac{a}{\Delta x^{2}} u_{i-1, j, k}+ \\
& \frac{c}{\Delta z^{2}} u_{i, j, k-1}+\left(-\frac{2 a}{\Delta x^{2}}-\frac{2 b}{\Delta y^{2}}-\frac{2 c}{\Delta z^{2}}-\frac{d}{\Delta x}-\right. \\
& \left.\frac{e}{\Delta y}-\frac{g}{\Delta z}+h\right) u_{i, j, k}=f(x, y, z)
\end{aligned}
$$

\subsection{Backward Difference Scheme - BDS}

In a similar way, by substituting the Eqs. (9) and (12) in (1), we obtain the backward difference scheme

$$
\begin{aligned}
& \frac{a}{\Delta x^{2}} u_{i+1, j, k}+\frac{b}{\Delta y^{2}} u_{i, j+1, k}+\frac{c}{\Delta z^{2}} u_{i, j, k+1}+ \\
& \left(\frac{a}{\Delta x^{2}}-\frac{d}{\Delta x}\right) u_{i-1, j, k}+\left(\frac{b}{\Delta y^{2}}-\frac{e}{\Delta y}\right) u_{i, j-1, k}+ \\
& \left(\frac{c}{\Delta z^{2}}-\frac{g}{\Delta z}\right) u_{i, j, k-1}+\left(-\frac{2 a}{\Delta x^{2}}-\frac{2 b}{\Delta y^{2}}-\frac{2 c}{\Delta z^{2}}+\frac{d}{\Delta x}+\right. \\
& \left.\frac{e}{\Delta y}+\frac{g}{\Delta z}+h\right) u_{i, j, k}=f(x, y, z)
\end{aligned}
$$

\subsection{Central Difference Scheme - CDS}

The central difference scheme is obtained by combination of Esq. (10), (12) and Eq. (1)

$$
\begin{aligned}
& \left(\frac{a}{\Delta x^{2}}+\frac{d}{2 \Delta x}\right) u_{i+1, j, k}+\left(\frac{b}{\Delta y^{2}}+\frac{e}{2 \Delta y}\right) u_{i, j+1, k}+ \\
& \left(\frac{c}{\Delta z^{2}}+\frac{g}{2 \Delta z}\right) u_{i, j, k+1}+\left(\frac{a}{\Delta x^{2}}-\frac{d}{2 \Delta x}\right) u_{i-1, j, k}+\left(\frac{b}{\Delta y^{2}}-\right. \\
& \left.\frac{e}{2 \Delta y}\right) u_{i, j-1, k}+\left(\frac{c}{\Delta z^{2}}-\frac{g}{2 \Delta z}\right) u_{i, j, k-1}+\left(-\frac{2 a}{\Delta x^{2}}-\frac{2 b}{\Delta y^{2}}-\right. \\
& \left.\frac{2 c}{\Delta z^{2}}+h\right) u_{i, j, k}=f(x, y, z)
\end{aligned}
$$

\section{NUMERICAL APPLICATIONS}

The numerical solution of the linear Equations (13), (14) and (15) was obtained by the utilization of the Gauss-Seidel Method with error $\leq 10^{-7}$ (Barroso et. all, 1987). In the utilization of this method only the non zeroes coefficients of the matrix need to be stored. In all applications the delta are all of the same size: $\Delta \mathrm{x}=\Delta \mathrm{y}=\Delta \mathrm{z}=\mathrm{h}$, and the domain will be an hexahedra of unitary side.

The first application is a case of convectiondiffusion equation in which all coefficients are unitary constants in the whole domain. The $\mathrm{L}_{2}$-norm of the error is calculated (Dhatt and Touzot (1984), Romão et all (2008)) in order to analyze the errors in the numerical solution. Also the maximum error is analyzed by the evaluation of the $\mathrm{L}_{\infty}$-norm. The $\mathrm{L}_{2}$ norm of the error was defined like in (Zlhmal, 1978):

$$
\|e\|=\left[\left(\sum_{i=1}^{\text {Nnost }} e_{i}^{2}\right) / \text { Nnost }\right]^{1 / 2} .
$$

In this equation, Nnost is the total number of nodes in the mesh and $e_{i}=\left|T_{(\text {num })_{i}}-T_{(\text {an })_{i}}\right|$, where $T_{\text {(num) }}$ is the result from the numerical solution and $T_{(a n)}$ is the result form the analytical solution respectively. The $\mathrm{L}_{2}$ norm presented a overview of error, while the $\mathrm{L}_{\infty}$ norm a view point of error.

The same is done in the second and third applications, but the coefficients of the convective terms are functions of number Reynolds, so that the third application the coefficients also depend on the space. The results of second application are compared with results from Gupta and Zhang (2000). The same size $h$ of discretization of Gupta was used in this work. The applications 1 at 3 are defined in domain $\Omega=[0,1]^{3}$, with $\Omega \in \mathfrak{R}$.

Application 1. In this case, the convectiondiffusion equation simplifies to:

$$
\frac{\partial^{2} u}{\partial x^{2}}+\frac{\partial^{2} u}{\partial y^{2}}+\frac{\partial^{2} u}{\partial z^{2}}+\frac{\partial u}{\partial x}+\frac{\partial u}{\partial y}+\frac{\partial u}{\partial z}=0
$$

subject to the Dirichlet boundary condition.

The analytical solution for the above equation is (Hon and Chen, 2003),

$$
u(x, y, z)=e^{-x}+e^{-y}+e^{-z}
$$

The calculated norms are presented in Tables 1 and 2. The first column of the tables is the size the spatial discretization; the second column show the number of non zeros coefficients in the linear system; the third the number of points in the domain and the last three columns are the norms of the errors. 
Table $1 . L_{2}$-norm of the errors in the numerical solutions of the three FDM considered.

\begin{tabular}{|c|c|c|c|c|c|}
\hline \multirow{2}{*}{$h$} & \multirow{2}{*}{ NCNN } & \multirow{2}{*}{ Nnodes } & \multicolumn{3}{|c|}{ L $_{\mathbf{2}}$ Norm } \\
\cline { 4 - 6 } & & & FDS & BCS & CDS \\
\hline $1 / 5$ & 600 & 216 & $2,87 \mathrm{E}-03$ & $3,74 \mathrm{E}-03$ & $1,08 \mathrm{E}-04$ \\
\hline $1 / 8$ & 2787 & 729 & $2,16 \mathrm{E}-03$ & $2,55 \mathrm{E}-03$ & $4,90 \mathrm{E}-05$ \\
\hline $1 / 10$ & 5705 & 1331 & $1,83 \mathrm{E}-03$ & $2,09 \mathrm{E}-03$ & $3,29 \mathrm{E}-05$ \\
\hline $1 / 16$ & 25163 & 4913 & $1,25 \mathrm{E}-03$ & $1,36 \mathrm{E}-03$ & $1,43 \mathrm{E}-05$ \\
\hline $1 / 20$ & 50415 & 9261 & $1,02 \mathrm{E}-03$ & $1,10 \mathrm{E}-03$ & $1,00 \mathrm{E}-05$ \\
\hline $1 / 32$ & 214683 & 35937 & $6,68 \mathrm{E}-04$ & $7,03 \mathrm{E}-04$ & $6,84 \mathrm{E}-06$ \\
\hline $1 / 64$ & 1774907 & 274625 & $3,34 \mathrm{E}-04$ & $3,68 \mathrm{E}-04$ & $1,46 \mathrm{E}-05$ \\
\hline $1 / 100$ & 6852095 & 1030301 & $1,70 \mathrm{E}-04$ & $2,82 \mathrm{E}-04$ & $5,57 \mathrm{E}-05$ \\
\hline
\end{tabular}

By inspection of tables 1 and 2, as expected, the mesh refinement reduce the value of the error, the central difference yielding to better results which with $\mathrm{h}=0,2$ already presents a maximum error and a $\mathrm{L}_{2}$-norm of order $10^{-4}$. In this first application convection and diffusion are of the same order of importance. In the next two applications the convection is predominant in order to analyze the robustness of the methods. Convective dominant problems present difficulties to numerical methods in general.

Table 2. $\mathrm{L}_{\infty}$-norm of the errors in the numerical solutions of the three FDM considered.

\begin{tabular}{|c|c|c|c|c|c|}
\hline \multirow{2}{*}{$\mathbf{h}$} & \multirow{2}{*}{ NCNN } & \multirow{2}{*}{ Nnodes } & \multicolumn{3}{|c|}{$\mathbf{L}_{2}$ Norm } \\
\cline { 4 - 6 } & & & FDS & BCS & CDS \\
\hline $1 / 5$ & 600 & 216 & $8,62 \mathrm{E}-03$ & $1,13 \mathrm{E}-02$ & $3,27 \mathrm{E}-04$ \\
\hline $1 / 8$ & 2787 & 729 & $5,70 \mathrm{E}-03$ & $6,76 \mathrm{E}-03$ & $1,29 \mathrm{E}-04$ \\
\hline $1 / 10$ & 5705 & 1331 & $4,78 \mathrm{E}-03$ & $5,47 \mathrm{E}-03$ & $8,60 \mathrm{E}-05$ \\
\hline $1 / 16$ & 25163 & 4913 & $3,12 \mathrm{E}-03$ & $3,39 \mathrm{E}-03$ & $3,62 \mathrm{E}-05$ \\
\hline $1 / 20$ & 50415 & 9261 & $2,51 \mathrm{E}-03$ & $2,69 \mathrm{E}-03$ & $2,55 \mathrm{E}-05$ \\
\hline $1 / 32$ & 214683 & 35937 & $1,59 \mathrm{E}-03$ & $1,67 \mathrm{E}-03$ & $1,85 \mathrm{E}-05$ \\
\hline $1 / 64$ & 1774907 & 274625 & $7,69 \mathrm{E}-04$ & $8,66 \mathrm{E}-04$ & $4,25 \mathrm{E}-05$ \\
\hline $1 / 100$ & 6852095 & 1030301 & $3,58 \mathrm{E}-04$ & $6,88 \mathrm{E}-04$ & $1,62 \mathrm{E}-04$ \\
\hline
\end{tabular}

In the routine used to solve the linear system, only non zero coefficients (NCNN - number of coefficients non nulls) need to be storage. For example, in a mesh with $\mathrm{h}=0,05, \mathrm{NCNN}=50.415$ and Nnodes $=9.261$ (Nnodes $=$ number of nodes) if a full matrix was assembled, for the linear systems (13), (14) and (15) one would have in a 9.261x9.261, 85.766.121 coefficients to be storage. Storing only the nonzero elements, the number of coefficients to be storage reduces to 50.415 , less than 1 percent of the full matrix, with a significant reduction in the computational cost.

We also noted in tables 1 and 2, that when using a mesh with $h=1 / 100$, the results begin to be less than the precision of mesh $h=1 / 64$, though not presented in this work, for a mesh $h=1 / 200$ precision now falls to values close to $10^{-3}$, demonstrating that excessive refinement do not always have better results (for CDS).

Application 2. In this application the convective coefficients are function of the Reynolds numbers and the equation considered is of the form:

$$
\begin{aligned}
& \frac{\partial^{2} u}{\partial x^{2}}+\frac{\partial^{2} u}{\partial y^{2}}+\frac{\partial^{2} u}{\partial z^{2}}-(\operatorname{Re} \cos \alpha \cos \beta) \frac{\partial u}{\partial x}- \\
& (\operatorname{Re} \cos \alpha \operatorname{sen} \beta) \frac{\partial u}{\partial y}-(\operatorname{Resen} \alpha) \frac{\partial u}{\partial z}=f(x, y, z)
\end{aligned}
$$

with $\alpha=35^{\circ}, \beta=45^{\circ}$ and subject to the Dirichlet boundary condition.

The analytical solution is (Gupta and Zhang, 2000),

$$
u(x, y, z)=\operatorname{sen} \pi \cdot x \cdot \operatorname{sen} \pi \cdot y \cdot \operatorname{sen} \pi \cdot z .
$$

Table 3. Maximum error to $\mathrm{Re}=1$.

\begin{tabular}{|c|c|c|c|c|}
\hline h & FDS & BDS & CDS & $\begin{array}{c}\text { Gupta } \\
\text { 2000, } \\
\text { standard } \\
\text { upwind }\end{array}$ \\
\hline $1 / 16$ & $2,15 \mathrm{E}-02$ & $1,44 \mathrm{E}-02$ & $3,43 \mathrm{E}-03$ & $1,45 \mathrm{E}-02$ \\
\hline $1 / 32$ & $9,85 \mathrm{E}-03$ & $8,10 \mathrm{E}-03$ & $7,97 \mathrm{E}-04$ & $8,09 \mathrm{E}-03$ \\
\hline $1 / 64$ & $4,67 \mathrm{E}-03$ & $4,31 \mathrm{E}-03$ & $1,62 \mathrm{E}-04$ & $4,28 \mathrm{E}-03$ \\
\hline
\end{tabular}

Table 4. Maximum error to $\mathrm{Re}=10$.

\begin{tabular}{|c|c|c|c|c|}
\hline h & FDS & BDS & CDS & $\begin{array}{c}\text { Gupta } \\
\text { 2000, } \\
\text { standard } \\
\text { upwind }\end{array}$ \\
\hline $1 / 16$ & $1,70 \mathrm{E}-01$ & $1,27 \mathrm{E}-01$ & $4,32 \mathrm{E}-03$ & $1,28 \mathrm{E}-01$ \\
\hline $1 / 32$ & $7,88 \mathrm{E}-02$ & $6,81 \mathrm{E}-02$ & $3,50 \mathrm{E}-04$ & $6,82 \mathrm{E}-02$ \\
\hline $1 / 64$ & $3,79 \mathrm{E}-02$ & $1,19 \mathrm{E}-02$ & $2,66 \mathrm{E}-04$ & $3,54 \mathrm{E}-02$ \\
\hline
\end{tabular}

Table 5. Maximum error to $\mathrm{Re}=100$.

\begin{tabular}{|c|c|c|c|c|}
\hline h & FDS & BDS & CDS & $\begin{array}{c}\text { Gupta } \\
\mathbf{2 0 0 0 ,} \\
\text { standard } \\
\text { upwind }\end{array}$ \\
\hline $1 / 16$ & $8,47 \mathrm{E}-01$ & $2,71 \mathrm{E}-01$ & $6,11 \mathrm{E}-03$ & $2,71 \mathrm{E}-01$ \\
\hline $1 / 32$ & $1,11 \mathrm{E}-01$ & $1,48 \mathrm{E}-01$ & $1,52 \mathrm{E}-03$ & $1,48 \mathrm{E}-01$ \\
\hline $1 / 64$ & $8,87 \mathrm{E}-02$ & $7,82 \mathrm{E}-02$ & $3,81 \mathrm{E}-04$ & $7,82 \mathrm{E}-02$ \\
\hline
\end{tabular}

Tables 3 to 5 show the results of the present simulation compared with the analytical solution from Gupta (2000). Although, the present results are less accurated than the results from Gupta (2000), we have used only first order discretization (FDS and BDS) and second order discretization (CDS), while Gupta has used an upwind scheme with identical 
results to those presented this work backward scheme.

In tables 3 to 5 , it can be observed that when the Reynolds number increases the errors of the present simulations are of the same (or better) order of accuracy of the results from Gupta (2000), being better at CDS. For this Reynolds number the convection already predominate over the diffusion.

Table 6. $\mathrm{L}_{2}$ Norm of error to $\mathrm{Re}=1$.

\begin{tabular}{|c|c|c|c|}
\hline $\mathbf{h}$ & FDS & BDS & CDS \\
\hline $1 / 16$ & $6,97 \mathrm{E}-03$ & $4,68 \mathrm{E}-03$ & $1,04 \mathrm{E}-03$ \\
\hline $1 / 32$ & $3,33 \mathrm{E}-03$ & $2,74 \mathrm{E}-03$ & $2,69 \mathrm{E}-04$ \\
\hline $1 / 64$ & $1,61 \mathrm{E}-03$ & $1,49 \mathrm{E}-03$ & $5,56 \mathrm{E}-05$ \\
\hline
\end{tabular}

Table 7. $\mathrm{L}_{2}$ Norm of error to $\mathrm{Re}=10$.

\begin{tabular}{|c|c|c|c|}
\hline $\mathbf{h}$ & FDS & BDS & CDS \\
\hline $1 / 16$ & $5,38 \mathrm{E}-02$ & $4,03 \mathrm{E}-02$ & $1,34 \mathrm{E}-03$ \\
\hline $1 / 32$ & $2,59 \mathrm{E}-02$ & $2,25 \mathrm{E}-02$ & $1,08 \mathrm{E}-03$ \\
\hline $1 / 64$ & $1,27 \mathrm{E}-02$ & $3,53 \mathrm{E}-02$ & $8,68 \mathrm{E}-05$ \\
\hline
\end{tabular}

Table 8. $\mathrm{L}_{2}$ Norm of error to $\mathrm{Re}=100$.

\begin{tabular}{|c|c|c|c|}
\hline $\mathbf{h}$ & FDS & BDS & CDS \\
\hline $1 / 16$ & $1,04 \mathrm{E}-01$ & $8,17 \mathrm{E}-02$ & $1,96 \mathrm{E}-03$ \\
\hline $1 / 32$ & $6,30 \mathrm{E}-02$ & $4,63 \mathrm{E}-02$ & $5,11 \mathrm{E}-04$ \\
\hline $1 / 64$ & $2,76 \mathrm{E}-02$ & $2,47 \mathrm{E}-02$ & $1,30 \mathrm{E}-04$ \\
\hline
\end{tabular}

In tables 6 to 8 , one notes that the average error introduced by the $\mathrm{L}_{2}$ norm is around the same order of accuracy of the maximum error introduced by the $\mathrm{L}_{\infty}$ norm.

Application 3. In this application the convective coefficients are function of the Reynolds number as well as of the space $(x, y, z)$ and the equation is of the form:

$$
\frac{\partial^{2} u}{\partial x^{2}}+\frac{\partial^{2} u}{\partial y^{2}}+\frac{\partial^{2} u}{\partial z^{2}}+(\text { Resenysen } z \cos x) \frac{\partial u}{\partial x}+
$$

$(\operatorname{Resen} x \operatorname{sen} z \cos y) \frac{\partial u}{\partial y}+(\operatorname{Resen} x \operatorname{sen} y \cos z) \frac{\partial u}{\partial z}=f$

with $f=f(x, y, z)$. The analytical solution is,

$$
u(x, y, z)=\cos (4 x+6 y+8 z) .
$$

Table 9. Maximum error to $\mathrm{Re}=1$.

\begin{tabular}{|c|l|l|l|}
\hline $\mathbf{h}$ & FDS & BDS & CDS \\
\hline $1 / 8$ & $6,52 \mathrm{E}-02$ & $9,33 \mathrm{E}-02$ & $7,72 \mathrm{E}-02$ \\
\hline $1 / 16$ & $1,44 \mathrm{E}-02$ & $2,81 \mathrm{E}-02$ & $1,90 \mathrm{E}-02$ \\
\hline $1 / 32$ & $2,99 \mathrm{E}-03$ & $9,49 \mathrm{E}-03$ & $4,72 \mathrm{E}-03$ \\
\hline $1 / 64$ & $1,67 \mathrm{E}-03$ & $3,67 \mathrm{E}-03$ & $1,15 \mathrm{E}-03$ \\
\hline
\end{tabular}

Table 10. $\mathrm{L}_{2}$ Norm of error to $\mathrm{Re}=1$.

\begin{tabular}{|c|l|l|l|}
\hline $\mathbf{h}$ & FDS & BDS & CDS \\
\hline $1 / 8$ & $2,36 \mathrm{E}-02$ & $3,42 \mathrm{E}-02$ & $2,87 \mathrm{E}-02$ \\
\hline $1 / 16$ & $5,18 \mathrm{E}-03$ & $1,06 \mathrm{E}-02$ & $7,69 \mathrm{E}-03$ \\
\hline $1 / 32$ & $1,00 \mathrm{E}-03$ & $3,53 \mathrm{E}-03$ & $2,00 \mathrm{E}-03$ \\
\hline $1 / 64$ & $4,78 \mathrm{E}-04$ & $1,31 \mathrm{E}-03$ & $5,09 \mathrm{E}-04$ \\
\hline
\end{tabular}

In tables 9, 11 and 13 are presented the norms $L_{\infty}$ of error while tables 10,12 and 14 are presented $L_{2}$ norms of error for values of h equal to $1 / 8,1 / 16,1 / 32$ and 1/64 for the three schemes proposed in this paper. Again, the CDS stands before the other two schemes, but for the $L_{2}$ norm the FDS has order of accuracy consistent with the results of the CDS in almost all the refinements.

Table 11. Maximum error to $\mathrm{Re}=10$.

\begin{tabular}{|c|l|l|l|}
\hline $\mathbf{h}$ & FDS & BDS & CDS \\
\hline $1 / 8$ & $1,34 \mathrm{E}-01$ & $3,52 \mathrm{E}-01$ & $9,28 \mathrm{E}-02$ \\
\hline $1 / 16$ & $8,44 \mathrm{E}-02$ & $1,39 \mathrm{E}-01$ & $2,27 \mathrm{E}-02$ \\
\hline $1 / 32$ & $4,76 \mathrm{E}-02$ & $6,10 \mathrm{E}-02$ & $5,74 \mathrm{E}-03$ \\
\hline $1 / 64$ & $2,53 \mathrm{E}-02$ & $2,86 \mathrm{E}-02$ & $1,42 \mathrm{E}-03$ \\
\hline
\end{tabular}

Table 12. $L_{2}$ Norm of error to $\operatorname{Re}=10$.

\begin{tabular}{|c|l|l|l|}
\hline $\mathbf{h}$ & FDS & BDS & CDS \\
\hline $1 / 8$ & $3,43 \mathrm{E}-02$ & $9,40 \mathrm{E}-02$ & $3,37 \mathrm{E}-02$ \\
\hline $1 / 16$ & $2,28 \mathrm{E}-02$ & $3,93 \mathrm{E}-02$ & $9,04 \mathrm{E}-03$ \\
\hline $1 / 32$ & $1,36 \mathrm{E}-02$ & $1,79 \mathrm{E}-02$ & $2,35 \mathrm{E}-03$ \\
\hline $1 / 64$ & $7,46 \mathrm{E}-03$ & $8,57 \mathrm{E}-03$ & $6,02 \mathrm{E}-04$ \\
\hline
\end{tabular}

The highlight negative is that the BDS, using the Gauss-Seidel to solve the linear system, showed no convergence results for meshes with $\mathrm{h}$ equal to $1 / 8$ and $1 / 16$ for a $\operatorname{Re}=100$. For meshes with $\mathrm{h}$ equal to $1 / 32$ and $1 / 64$, in turn, the method converged normally.

Table 13. Maximum error to $\mathrm{Re}=100$.

\begin{tabular}{|c|l|c|c|}
\hline $\mathbf{h}$ & FDS & BDS & CDS \\
\hline $1 / 8$ & $5,01 \mathrm{E}-01$ & Not converge & $2,14 \mathrm{E}-01$ \\
\hline $1 / 16$ & $2,72 \mathrm{E}-01$ & Not converge & $4,98 \mathrm{E}-02$ \\
\hline $1 / 32$ & $1,48 \mathrm{E}-01$ & $2,06 \mathrm{E}-01$ & $1,25 \mathrm{E}-02$ \\
\hline $1 / 64$ & $7,79 \mathrm{E}-02$ & $8,87 \mathrm{E}-02$ & $3,13 \mathrm{E}-03$ \\
\hline
\end{tabular}

Table 14. $\mathrm{L}_{2}$ Norm of error to $\mathrm{Re}=100$.

\begin{tabular}{|c|l|c|c|}
\hline $\mathbf{h}$ & FDS & BDS & CDS \\
\hline $1 / 8$ & $1,57 \mathrm{E}-01$ & Not converge & $7,02 \mathrm{E}-02$ \\
\hline $1 / 16$ & $9,35 \mathrm{E}-02$ & Not converge & $1,81 \mathrm{E}-02$ \\
\hline $1 / 32$ & $5,15 \mathrm{E}-02$ & $6,15 \mathrm{E}-02$ & $4,67 \mathrm{E}-03$ \\
\hline $1 / 64$ & $2,72 \mathrm{E}-02$ & $2,95 \mathrm{E}-02$ & $1,19 \mathrm{E}-03$ \\
\hline
\end{tabular}

For this case, was tested meshes with h equal to $1 / 100$ and $1 / 200$, but the results are worse than the precision shown for the mesh $h=1 / 64$ for the three variations of the Reynolds number, thus showing that not always the constant refinement of the mesh always present better results. 


\section{CONCLUSIONS AND FUTURE WORK}

The Finite Difference method is a powerful tool in solution of convection-diffusion problems. The numerical solution of this kind of problem generally is affected by numerical oscillations when the Reynolds number increases. The obtained results demonstrated that for error of order $10^{-2}$ or $10^{-3}$, discretization of first or second order already can be satisfactory. With this order of error the simulations are relatively of low cost and of easy implementation, for example, in Fortran language.

In next works, more general problems to which analytical solutions are not known will be analyzed. With computers of great capacity of RAM, more refined meshes shall be considered and more realistic problems where the velocity field needs to be obtained also will be considered.

\section{ACKNOWLEDGMENTS}

The present work was supported by the National Council of Scientific Development and Technology $\mathrm{CNPq}$ - Brasil through a scholarship to the first author.

\section{REFERENCES}

Barroso, C. B., Barroso, M. M. A., Campos Filho, F. F., Carvalho, M. L. B. C. and Maia, M. L., 1987, Cálculo Numérico - Com Aplicações, 2 ${ }^{\mathrm{a}}$ edição, Editora Harbra, Brasil. (in Portuguese)

Chung, T. J., 2002, "Computational Fluid Dynamics”, Cambridge University Press.

Compaq Visual Fortran (CVF), Copyright 2000, Compaq Computer Corporation, Additional Information: Compaq Visual Fortran Professional Edition.

Dhatt, G. and Touzot, G., 1984, The Finite Element Method, John Wiley \& Sons.

Fortuna, A. O., 2000, Técnicas Computacionais para Dinâmica dos Fluidos - Conceitos Básicos e Aplicações, São Paulo: Editora da Universidade de São Paulo.

Gupta, M. M. and Zhang J., 2000, High accuracy multipgrid solution of the $3 \mathrm{D}$ convection-diffusion equation, Applied Mathematics and Computation, Vol. 113, pp. 249 - 274.

Hon, Y. C. and Chen, W., 2003, Boundary knot method for 2D and 3D Helmholtz and convectiondiffusion problems under complicated geometry, International Journal for Numerical Methods in Engineering, 56, pp. 1931-1948.

Hsu, P. T., 2006, Estimating the boundary condition in a 3D inverse hyperbolic heat conduction problem, Applied Mathematics and Computation, Vol. 177, pp. 453-464.

Jiang, B. N., 1998, The Least-Squares Finite Element Method - Theory and Applications in
Computational Fluid Dynamics and Electromagnetics, Springer.

Romão, E. C, Moura, L. F. M. and Campos-Silva, J. B., 2008, A comparasion of time discretization methods in the solution of a parabolic equation, DINCON 2008, Presidente Prudente-SP, Brazil.

Romão, E. C., Moura, L. F. M. ; Campos-Silva, J. B., 2008, Analysis of Error in the Solution of the 2-D Diffusion Equation by Finite Element Methods. TEMA - Tendências em Matemática Aplicada e Computacional, Vol. 2, pp. 287-298. (Seleta Dincon 2008)

Smith, G. D., 1971, Numerical Solution of Partial Differential Equations, Oxford Mathematical Handbooks, NewYork.

Zlhmal, M., 1978, Superconvergence and reduced integration in the finite element method. Math. and Comput. Vol. 32, p. 663.

Yang, M. T., Park, K. H., Banerjee P. K., 2002, 2D and 3D transient heat conduction analysis by BEM via particular integrals, Comput. Methods Appl. Mech. Engrg. Vol. 191, pp. 1701-1722.

Received: July 13, 2008

Revised: August 13, 2008

Accepted: September 13, 2008 